\title{
O sexo dos anjos: um olhar sobre a anatomia $e$ a produção do sexo (como se fosse) natural
}

\author{
Paula Sandrine Machado **
}

\section{Resumo}

Este artigo analisa as representações corporais e práticas sociais acionadas no que se refere às crianças $e$ jovens intersex, contrastando a perspectiva de profissionais médicos com a dos familiares envolvidos. Parte-se de dois eixos analíticos: o olhar generificado sobre a anatomia $e$ as visibilidades/invisibilidades do sexo. Os argumentos centrais propostos são que o sexo é tão construído na cultura quanto o gênero e que as fronteiras entre o natural e o não-natural são facilmente borradas quando se trata de definí-las a partir do que é considerado dentro ou fora das normas sociais.

Palavras-chave: Intersexo, Sexo, Gênero, Representações Corporais, Antropologia Médica.

\footnotetext{
* Recebido para publicação em fevereiro de 2005, aprovado em março de 2005.

** Doutoranda em Antropologia Social na UFRGS e Pesquisadora Associada ao Núcleo de Pesquisas em Antropologia do Corpo e da Saúde (NUPACS)/UFRGS, Porto Alegre, RS, Brasil. paulasandrine@yahoo.com.br
} 
O sexo dos anjos

The Sex of Angels: Analyzing Anatomy and the Construction of (as if it Were) a Natural Sex

\begin{abstract}
This paper analyzes body representations and social practices related to intersex children and teenagers by contrasting the viewpoints of medical doctors and the patients' relatives. It is based upon two analytical categories: the gendered view of anatomy and the visibility/invisibility of sex. The main arguments suggested here are that sex is as culturally-built as gender, and that the boundaries between the natural and not-natural are easily blurred when it comes to defining what fits and what does not fit social norms.
\end{abstract}

Key Words: Intersex, Sex, Gender, Body Representations, Medical Anthropology. 
A discussão em torno do "hermafroditismo" não é algo exatamente novo. Ela tem ocupado, há séculos, o pensamento de filósofos, médicos, juristas, entre outros. De acordo com Anne Fausto-Sterling ${ }^{1}$, a palavra hermafrodita surgiu na Grécia, representando uma combinação dos nomes de dois deuses: Hermes (o filho de Zeus) e Afrodite (deusa da beleza e do amor sexual). Um dos mitos de origem do primeiro hermafrodita, conforme aponta a autora, sugere que Hermes e Afrodite tiveram um filho de beleza estonteante, de tal forma que teria despertado a paixão de uma ninfa. A ninfa, tomada por seus sentimentos, colou-se ao corpo de Hermaphroditos, e os dois tornaram-se um.

Foucault ${ }^{2}$, em seus estudos sobre as definições de "anormalidade" e "monstruosidade" do século XIX, aponta que os hermafroditas constituíam um tipo de "monstro" privilegiado na Idade Clássica. O autor analisa as diferentes medidas regulatórias e "reparadoras" que recaíam sobre esses indivíduos, ora pensados como "imperfeições da natureza", ora como possíveis desviantes morais. Outro autor, Mircea Eliade ${ }^{3}$, em seus apontamentos sobre os comportamentos religiosos e os valores espirituais nãoeuropeus, também mostra como a figura do andrógino ou a androginia tem sido uma preocupação que desafia o pensamento ocidental.

Analisando a construção do mito do andrógino em diversas culturas não ocidentais, Eliade deixa claro que essas possuem estruturas explicativas para conceber e lidar com o fenômeno. A idéia da totalidade, da união dos opostos em um só ser, é o que fundamenta, em última instância, o pressuposto da androginia dos seres divinos. Dentro dessa lógica, o sexo dos anjos, expressão

1 Fausto-Sterling, Anne. Sexing the Body: Gender Politics and the Construction of Sexuality. New York, Basic Books, 2000, p.32.

2 Foucault, Michel. Aula de 22 de janeiro de 1975. In: FOUCAULT, Michel. Os Anormais. São Paulo, Martins Fontes, 2001, pp.69-100.

3 EliADE, Mircea. Mefistófeles e o Andrógino ou o mistério da totalidade. In: Mefistófeles e o Andrógino: comportamentos religiosos e valores espirituais náoeuropeus. $2^{\text {a }}$ ed. São Paulo, Martins Fontes, 1999, pp.77-129. 
O sexo dos anjos

que dá nome a esse artigo, não remeteria ao fato de que anjos são seres sem sexo, sem idade ou outros atributos humanos. Pelo contrário, a figura do anjo, que alude à divindade, é justamente capaz de traduzir a possibilidade da existência de uma variabilidade de sexos. Da mesma forma que ocorre com a história de Hermaphroditos, destaca-se, aqui, um contraponto em relação à idéia hegemônica da inevitabilidade de pensar o sexo como dicotômico.

No que se refere à sociedade contemporânea, o dilema frente à androginia aparece recolocado no atual debate sobre a decisão da cirurgia em casos de pessoas nascidas com o que, na linguagem biomédica, denomina-se "genitália ambígua" ou, mais atualmente, "genitália incompletamente formada". Também chamados de "estados intersexuais", essas definições se referem, de forma geral, a corpos de crianças nascidas com a genitália externa e/ou interna nem claramente feminina, nem claramente masculina. ${ }^{4}$ De acordo com a literatura médica, os "estados intersexuais" podem ser divididos em quatro principais grupos: pseudo-hermafroditismo feminino; pseudo-hermafroditismo masculino; disgenesia gonadal mista; hermafroditismo verdadeiro. ${ }^{5}$ Atualmente, é difícil estimar sua incidência devido à existência de várias causas que podem levar ao intersexo, sendo que a apontada como a mais comum é a hiperplasia de suprarenal cuja incidência varia de 1/5000 na Europa a 1/15000 nos Estados Unidos. ${ }^{6}$

4 KESSLER, Suzanne J. The medical construction of gender: case management of intersexed infants. In: LASLETT, Barbara; KOHLSTEDT, Sally Gregory; LONGINO, Hellen; HAmmonds, Evelynn. (eds.) Gender and Scientific Authority. Chicago, University of Chicago Press, 1996, pp.340-363.

5 FreitAs, Fernando; PASsos, Eduardo Pandolfi; CunHA FILHO, João Sabino L. da. Estados Intersexuais. In: FreITAS, F.; MENKE, Carlos Henrique; RIVOIRE, Waldemar A.; PAssos, E.P. (orgs.) Rotinas em Ginecologia. Porto Alegre, Artmed, 2002.

${ }^{6}$ Braunwald, Eugene; FauCl, Anthony, S.; KASPER, Dennis L.; HaUSER, Stephen L.; LONGO, Dan L.; JAMESON, J. Larry. (eds.) Harrison - Medicina Interna. 15a Edição, Rio de Janeiro, McGraw-Hill, 2002, vol.2. Ativistas apontam que o número de crianças nascidas com a genitália ambígua (ou seja, que não se pode 
Assim, do monstro moral do século XIX, vemos nascer, no final do século XX e início do século XXI, o indivíduo com a "genitália incompletamente formada", ou seja, aquele que recebe um diagnóstico médico e cujo problema de "inadequação genital" pode ser manejado por profissionais capacitados. O emprego da técnica justifica-se, nesse caso, para restaurar uma "natureza incompleta". Conforme sugere Paul Rabinow ${ }^{7}$ ao trabalhar com a ciência, emergem, face aos avanços da biotecnologia, identidades constituídas a partir dessa técnica - no caso, a cirurgia reparadora dos genitais e todo o aparato da medicalização hormonal. Dessa forma, o debate em torno da intersexualidade não se restringe aos profissionais de saúde. Quando se trata de pensar como se definem homens e mulheres, como se percebe a anatomia dos genitais e como se classifica uma condição física como normal ou patológica, necessariamente, a lógica médica entra em negociação $e$, por vezes, em contradição, com a lógica das próprias pessoas intersex e de seus familiares.

Neste artigo, serão examinadas as representações corporais e práticas sociais acionadas no que se refere a crianças e jovens intersex, contrastando a perspectiva dos profissionais médicos com a dos familiares envolvidos. A linha argumentativa condutora toma como pressuposto que o sexo é tão construído na cultura quanto o gênero e que as fronteiras entre o "natural" e o "não natural" são facilmente borradas quando se trata de defini-las a partir do que é considerado dentro ou fora das normas sociais. O argumento do sexo como "não natural" será analisado a partir de dois eixos: 1) o olhar generificado sobre a anatomia e 2) as visibilidades $e$ as invisibilidades do sexo.

reconhecer como masculina ou feminina), considerando todas as causas possíveis, atinge a cifra de uma em cada 2000. Esses números podem ser encontrados no site da Intersex Society of North América - www.isna.org.

7 RABINOW, Paul. Artificialidade e iluminismo: da sociobiologia à biossociabilidade. In: Antropologia da Razão: ensaios de Paul Rabinow. Rio de Janeiro, Relume Dumará, 1999, pp.135-157. 
O sexo dos anjos

No primeiro eixo, trata-se de operacionalizar o argumento de que o sexo é, desde sempre, marcado pelo gênero. Assim, os valores de quem olha e/ou classifica genitais interferem naquilo que estão vendo $e$, conseqüentemente, na nominação do que vêem. $\mathrm{E}$, conforme aponta Bourdieu ${ }^{8}$, o ato de nomear tem, em si mesmo, o efeito de criar. Dessa forma, se há, por um lado, uma construção, por outro ela é incorporada pelos atores sociais como natural. Percorrerei também nesse eixo de análise as diferentes definições do que seja "natural" para os profissionais médicos que estão inseridos nos processos de tomada de decisão e para as famílias das crianças. Existem elementos que demonstram como, no manejo médico dos corpos intersex, há uma espécie de aproximação entre a noção de "natural" $e$ aquilo que é considerado "ideal" de corpo dentro das normas sociais. ${ }^{9}$ Já a definição do "não natural" cola-se, com muita facilidade, à de "desvio" ou "anomalia".

No eixo sobre as visibilidades $e$ invisibilidades do sexo, articulo o que considerei como os dois níveis distintos onde as mesmas se apresentam: o social e o anatômico. O foco será dado na categoria ambigüidade, na forma como ela é significada de um lado para os profissionais médicos e, de outro, para as famílias das crianças intersex. Serão analisadas principalmente as percepções $e$ as representações acionadas nos casos que envolvem crianças com cariótipo $46 \mathrm{XX}^{10}$ e com o que é chamado pelos médicos de Hiperplasia Adrenal Congênita (HAC $)^{11}$, e crianças com cariótipo 46XY com Hipospádias e Criptorquidia. ${ }^{12}$

8 BourdiEu, Pierre. Ce que parler veut dire: L'économie des Échanges Linguistiques. Paris, Fayard, 1982.

9 KESSLER, Suzanne. Lessons from the Intersexed. New Jersey, Rutgers University Press, 1998.

${ }^{10}$ A sigla 46XX (ou 46XY) é uma convenção biomédica, onde 46 diz respeito ao número total de cromossomos de um indivíduo e XX ou XY referem-se a um dos pares desse conjunto, sendo chamados de "cromossomos sexuais".

${ }^{11}$ Adrenal é uma glândula que produz cortisol, andrógenos e outras substâncias. A Hiperplasia Adrenal Congênita caracteriza-se como a deficiência de uma 
Nesse eixo, buscarei ainda desenvolver um argumento proposto por Suzanne Kessler ${ }^{13}$ quando analisa os protocolos médicos no manejo de pessoas intersex: o de que os médicos percebem a si mesmos como "criando técnicas" e não "cultura". Considerar esses atores sociais como produtores de cultura é algo operativo para pensar que as definições sobre o "sexo verdadeiro" de uma criança estão, elas mesmas, produzindo o sexo. Nesse sentido, levantar questões sobre o tema engendra não apenas uma discussão ética acerca das cirurgias precoces de correção de genitais ditos "ambíguos", como se insere num debate político em torno da suposta "naturalidade" das dicotomias de sexo e gênero.

Trata-se de uma pesquisa qualitativa, sócio-antropológica, na qual foi adotado o método etnográfico, considerado a partir da tradição inaugurada por Malinowski. ${ }^{14} \mathrm{O}$ material empírico privilegiado nas análises desse artigo é resultado de entrevistas informais com profissionais de saúde envolvidos nas decisões, especialmente cirurgiões, endocrinologistas e psicólogos, bem como com os jovens que foram submetidos à cirurgia $e$ seus

enzima necessária para a produção de cortisol. Para compensar esse déficit, há um estímulo em toda a adrenal, resultando na produção excessiva de andrógenos. Em crianças com cariótipo 46XX, a exposição ao excesso de andrógenos ocasiona uma "virilização" da genitália externa, o que, entre outras conseqüências, faz com que o clitóris se apresente em dimensões anatômicas maiores que as esperadas para uma menina.

${ }^{12}$ Em crianças que apresentam um cariótipo 46XY, a hipospádia é caracterizada pela formação atípica da genitália externa masculina. Na linguagem médica, dizse que um pênis hipospádico é aquele em que o orifício do canal uretral não se localiza na ponta do pênis, estando na sua parte ventral e, em alguns casos, bem próximo à base do escroto. Combinada à criptorquidia, condição clínica na qual os testículos não desceram para a bolsa escrotal, a hipospádia é uma das situações caracterizadas como "genitália ambígua".

${ }^{13}$ KESSLER, S. Lessons from the... Op. cit., pp.124.

${ }^{14}$ MALINOWSKI, Bronislaw. Introdução: tema, método e objetivo desta pesquisa. In: Argonautas do Pacífico Ocidental: um relato do empreendimento e da aventura dos nativos nos arquipélagos da Nova Guiné Melanésia. São Paulo, Abril Cultural, 1976, pp.21-38. 
O sexo dos anjos

familiares. Parte dos dados provém das observações realizadas em um ambulatório de cirurgia/urologia pediátrica e em um ambulatório de endocrinologia pediátrica, bem como em reuniões de equipe e em discussões dos casos de mais difícil resolução médica.

Além disso, foram realizadas entrevistas individuais semiestruturadas com oito profissionais de saúde - dois psicólogos, dois cirurgiões pediátricos, um residente ${ }^{15}$ de cirurgia pediátrica, um endocrinologista pediátrico, um geneticista e um pediatra que se encontram envolvidos nessas decisões. ${ }^{16}$ Através da entrevista, buscou-se entender o processo de tomada de decisão $e$ os elementos pesados na situação. Os profissionais entrevistados trabalham no mesmo hospital ${ }^{17}$ e a maioria deles possui entre si uma antiga relação de trabalho.

Todos os nomes de pessoas foram trocados para preservar o seu anonimato. As crianças/jovens intersex receberão nomes de anjos, em função da simbologia sobre o sexo dos anjos já referida. Os familiares receberão nomes criados por mim. No que se refere aos profissionais de saúde, não utilizarei nem nomes fictícios, nem especificarei o sexo dos mesmos (optando por tratar todos pelo masculino e diferenciá-los em função da especialidade), por razões éticas. Ressalto, entretanto, que apenas um dos médicos é mulher

15 "Residente" é um médico já formado que está fazendo especialização no hospital. Todo residente da cirurgia pediátrica já é cirurgião geral e leva mais três anos (R1, R2 e R3) para concluir a cirurgia pediátrica.

${ }^{16}$ Todos os entrevistados assinaram um Termo de Consentimento Livre e Esclarecido, autorizando a utilização dos dados com a devida garantia de confidencialidade das informações concedidas. O projeto mais amplo da pesquisa, que se refere à tese de doutorado, foi avaliado e aprovado pelo Comitê de Ética em Pesquisa do hospital.

${ }^{17}$ Trata-se de um hospital-escola, com grande complexidade tecnológica, do RS. Nele é prestado, diariamente, atendimento a um vasto contingente populacional. No que se refere aos casos diagnosticados como "estados intersexuais", pôde-se identificar, via registros de prontuários, mais de 100 pessoas internadas nesse hospital de 1990 até 2003 , de várias idades e locais do estado. Isso significa uma média de 10 pessoas ao ano. 
Paula Sandrine Machado

e que, apesar da diferença de sexo, sua fala converge com a dos demais. Acredito, portanto, na possibilidade de considerar os pressupostos do campo médico, de forma abrangente, como marcadamente masculinos. ${ }^{18}$

Antes de partir para a análise do material empírico, é importante situar o tema da intersexualidade em um debate mais amplo que diz respeito às construções e desconstruções teóricoconceituais operadas em torno dos dimorfismos de sexo e gênero $^{19}$, ora mais ora menos essencializados no campo dos estudos em sexualidade.

\section{A (des)construção do sexo}

O sexologista John Money ficou bastante conhecido nas discussões em torno da sexualidade devido a sua teoria dos "papéis sexuais", através da qual propunha a diferenciação entre sexo biológico e sexo psíquico. Foi ele quem primeiro descreveu o caso de um bebê submetido a uma cirurgia de (re)construção genital, tornando-se uma referência no campo biomédico ${ }^{20}$ nesse assunto. David Reimer, que tinha um irmão gêmeo, fora vítima de uma complicação durante um procedimento de circuncisão, no qual seu pênis fora severamente queimado. Procurado pela

\footnotetext{
${ }^{18}$ SHIEBINGER, Londa. Skeletons in the Closet: the first illustrations of the female skeleton in eighteenth-century anatomy. In: GALLAGHER, C.; LAQUEUR, T. (eds.) The Making of the Modern Body: Sexuality and Society in the Nineteenth Century. California, University of California Press, 1987, pp.42-82; MARTIN, Emily. Science and the Construction of Gendered Bodies. In: LASLETT, B.; Kohlstedt, S. G.; Longino, H.; HAmmOnDS, E. (eds.) Gender and Scientific... Op.cit., pp.323-339; Miller, Merry N.; McGowen, K. Ramsey. The Painful Truth: Physicians are not Invincible. South Med. J., vol. 93, n 10, 2000, pp.966972.

${ }^{19}$ CORRÊA, Mariza. Não se nasce homem. Trabalho apresentado no Encontro "Masculinidades/Feminilidades", nos Encontros Arrábida 2004, Portugal, 2004.

${ }^{20} \mathrm{O}$ termo biomédico será utilizado fazendo-se referência aos conhecimentos da medicina ocidental moderna e áreas afins, como a biologia de uma forma geral e a psicologia, entre outras.
} 
O sexo dos anjos

família, Money sugeriu que a criança tivesse o sexo reformulado $e$ fosse transformada em uma menina. ${ }^{21}$ No relato do caso, algumas "precauções" são enfatizadas:

A primeira coisa a considerar era a identidade sexual da criança. Desde a concepção até a idade de 15 meses, todas as forças tinham dirigido consistentemente a criança rumo a uma diferenciação de identidade sexual masculina, exceto que a partir dos sete meses não houvera pênis para confirmar os outros determinantes sexuais. Entretanto, uma vez que a criança mal tinha começado a falar quando os pais se decidiram pela reformulação, havia uma excelente probabilidade da identidade sexual não estar ainda muito diferenciada na direção masculina. Isso era encorajador, mas havia também a questão das expectativas dos pais (...) quaisquer dúvidas enfraqueceriam a identificação da criança como menina e mulher. ${ }^{22}$

Durante um bom tempo, o caso de David foi utilizado como o argumento mais enfático a favor das cirurgias precoces em crianças nascidas com o que se costumou chamar de "genitália ambígua" ou intersexo, já que era considerado a "comprovação empírica" do seu sucesso. Kipnis e Diamond ${ }^{23}$, ambos médicos, criticaram o modelo centrado na cirurgia, apontando a insatisfação por ela gerada nas pessoas operadas, inclusive no próprio David Reimer, que se suicidou no início do mês de maio de 2004, aos 38 anos, após uma longa história de "correções" cirúrgicas. Em seu artigo, os autores questionam basicamente a falta de informação fornecida pelos médicos às pessoas $e$ a impossibilidade velada da medicina de fazer genitais "normais".

${ }^{21}$ MONEY, John e TUCKER, Patricia. Os papéis sexuais. São Paulo, Brasiliense, 1981

${ }^{22}$ ID., IB., pp.82-83.

${ }^{23}$ KIPNIS, Kenneth e DIAMOND, Milton. Pediatric Ethics and the Surgical Assignment of Sex. The Journal of Clinical Ethics. vol. 9, n 4, 1998, pp.398-410. 
Se, por um lado, o caso David levantava a discussão sobre o que era mais determinante para a "identidade sexual" de um indivíduo - que, para Money, era indiscutivelmente a socialização inequívoca na direção de um ou outro gênero e não o sexo biológico - por outro não colocava em questão a idéia hegemônica dos dimorfismos de gênero (masculino ou feminino) $e$ de sexo (homem ou mulher). Além disso, ainda que definidos como entidades diferentes, para Money, o sexo biológico deveria estar em conformidade com o sexo psíquico. Como aponta Mariza Corrêa ${ }^{24}$, em um artigo onde situa a história da intersexualidade na trajetória dos estudos de gênero, Money baseava-se no argumento segundo o qual uma "identidade sexual adequada", masculina ou feminina, deveria estar ancorada em uma anatomia, de homem ou de mulher, que não lhe parecesse contraditória.

Algum tempo já transcorreu desde a descrição do caso David, e não só a realidade social passou por transformações, como o próprio conhecimento produzido na área da sexualidade humana sofreu reformulações. Podemos encontrar uma série de trabalhos, no campo das Ciências Sociais, que possuem uma posição crítica no que se refere à suposta obviedade em que se assenta o dimorfismo sexual, mostrando que nem todas as sociedades percebem a diferença entre os sexos de forma dicotômica. ${ }^{25}$ Dessa perspectiva resulta o pressuposto de que pessoas compartilhando lógicas culturais diferentes nem sempre olham a anatomia da mesma forma.

Colocando em questão a idéia da inevitabilidade do dimorfismo sexual para o homem, Gilbert Herdt ${ }^{26}$ descreve, em um de seus artigos, os casos da República Dominicana e da Nova

${ }^{24}$ CORRÊA, M. Não se nasce... Op. cit.

${ }^{25}$ HeRDT, Gilbert. (ed.) Third Sex, Third Gender: Beyond Sexual Dimorphism in Culture and History. New York, Zone Books, 1993.

${ }^{26}$ ID. Mistaken Gender: 5-alpha Reductase Hermaphroditism and Biological Reductionism in Sexual Identity Reconsidered. American Anthropologist, vol.92, n², 1990, pp.433-446. 
O sexo dos anjos

Guiné, culturas baseadas em um código social que inclui três sexos ao invés de dois. Ele analisa a forma como, nessas duas sociedades, é dada visibilidade social a pessoas com um tipo específico de pseudohermafroditismo masculino, causado pela deficiência em uma enzima (5-alpha reductase), cuja conseqüência biológica mais evidente é o nascimento de crianças com cariótipo $\mathrm{XY}$ e genitália externa não virilizada, mas que passam a desenvolver caracteres masculinos na puberdade, quando há uma produção aumentada de testosterona capaz de, então, estimular a virilização. Na República Dominicana, por exemplo, essas crianças serão chamadas de guevedoche (que significa "pênis aos doze") e não são consideradas homens. Os guevedoche têm um outro estatuto social e biológico.

A partir dessas análises, $\mathrm{Herdt}^{27}$ propõe a existência de uma terceira categoria para pensar o sexo e com isso está, justamente, buscando desconstruir a idéia da "natureza binária" inscrita nos genitais. Assim, o "terceiro sexo" não é, para ele, mais uma categoria a ser fixada e essencializada nos corpos. De acordo com o autor, essa seria apenas uma estratégia teórico-conceitual no sentido de transcender a dicotomia, mostrando que nem todas as culturas se baseiam nas mesmas classificações anatômicas/ biológicas. O que deve ser ressaltado é que a existência de um terceiro, quarto ou quinto sexo é, para Herdt, sempre uma construção histórico-cultural.

Teóricas clássicas como Françoise Héritier ${ }^{28}$, por outro lado, apontam o papel da diferença anatômica e das diferenças em relação à reprodução entre homens e mulheres como fundamentais na percepção da diferença entre os sexos. É sobre essa oposição, segundo ela, que opera todo o pensamento da diferença $e$ sobre a qual se constroem, nas diversas culturas,

${ }^{27}$ ID. Preface.; Introduction: Third Sexes and Third Genders. In: Third Sex, Third... Op.cit., pp.11-81.

${ }^{28}$ HérITIER, Françoise. Masculino Feminino - $O$ pensamento da diferença. Lisboa, Instituto Piaget, 1998. 
variadas expectativas sociais e se atribuem diferentes valores a homens e mulheres. Assim, para Héritier, como para Bourdieu ${ }^{29}$, as diferenças anatômicas se transformam em diferenças socialmente significativas e essas diferenças se inscrevem, necessariamente, em uma matriz binária. Dessa forma, para ela ${ }^{30}$ ocorre que as categorizações binárias são um efeito da observação do dimorfismo sexual e não o contrário. Ainda que, por um lado, a autora seja capaz de desconstruir alguns essencialismos em relação ao gênero, não examina a própria oposição binária, naturalizando-a. Essa seria uma crítica também feita por Joan Scott ${ }^{31}$ a algumas teóricas do feminismo.

Meu argumento alinha-se ao de Joan Scott no que se refere ao fato de que, para ela, a "natureza" do sexo já está marcada, desde o princípio, por um olhar de gênero. O material empírico com o qual tenho trabalhado apresenta inegáveis indícios de que o sexo deixa de ser natural e que o modelo dicotômico é uma construção social, que se impõe como norma para todos os corpos. Isso equivale a dizer que não é necessariamente a partir da natureza que se criam as dicotomias, e sim que se aprende a perceber o mundo como dicotômico, restando pouca tolerância para a indefinição e a ambigüidade. Alguns fenômenos, como os descritos por $\mathrm{Herdt}^{32}$, e os que tenho observado empiricamente relacionados à intersexualidade, colocam em questão a naturalidade da dicotomia e nos permitem transcendê-la, mostrando como, de fato, existe sobre ela um processo de produção absolutamente sofisticado e enraizado no pensamento social de algumas culturas como a nossa.

${ }^{29}$ BouRdieu, Pierre. A dominação masculina. Rio de Janeiro, Bertrand Brasil, 1999.

${ }^{30}$ HÉRITIER, Françoise. Masculin/Féminin II - Dissoudre la hiérarchie. Paris, Odile Jacob, 2002.

${ }^{31}$ ScotT, Joan. Gênero: uma categoria útil de análise histórica. Educação e Realidade, vol. 20, n², 1995, pp.71-99.

32 HerdT, G. Mistaken Gender: 5-alpha... Op. cit. 
O sexo dos anjos

Assim, no que se refere à tomada de decisões no contexto das cirurgias "reparadoras" dos genitais de crianças intersex, a dicotomia é uma referência importante no momento de classificar os genitais de uma criança e marca a forma de olhar, tanto de médicos como de familiares de pessoas intersex. Por outro lado, como será apresentado a partir dos dois eixos de análise que proponho, os elementos postos em oposição nem sempre são os mesmos, já que nem sempre os olhares coincidem. Logo, é preciso apontar que discutir o sexo dos anjos recoloca questões para a discussão sexo-gênero e natureza-cultura, re-semantizando os termos em debate.

\section{A artificialidade cosmética do sexo: a construção do olhar sobre a anatomia}

Antes de iniciar a observação participante no ambulatório de cirurgia pediátrica do hospital, realizei um estudo exploratório em prontuários de algumas crianças, com registro de internações hospitalares no período situado entre os anos 1990 e 2003, submetidas à cirurgia "reparadora" dos genitais e que seguiram ou não em acompanhamento no referido hospital. Expressões como genitália de bom aspecto estético ou cosmético foram abundantemente encontradas nas descrições médicas (de alunos, residentes, médicos contratados ou professores) acerca da aparência dos genitais percebida a partir do exame físico daquelas crianças que já haviam sido submetidas a procedimentos cirúrgicos, como correções de hipospádias, clitoroplastias e vaginoplastias. $^{33}$

\footnotetext{
${ }^{33}$ A clitoroplastia é um procedimento cirúrgico que visa a "correção" de clitóris considerados de tamanhos e/ou formas anormais. Essa intervenção difere das outras duas técnicas anteriormente utilizadas: a clitorectomia (extirpação total do clitóris) e o sepultamento clitoriano. A vaginoplastia é um procedimento cirúrgico de "reparação" da vagina com o objetivo de construir o canal vaginal e os pequenos e grandes lábios.
} 
Confesso que fiquei um tanto intrigada com a utilização tão freqüente desses termos, mas fui percebendo, com minha inserção em campo, que a relação do "sucesso" cirúrgico com os mesmos não era fortuita. Além disso, somado a outros indícios percebidos em campo, fui reconhecendo um dos sentidos de importância crucial àqueles que são ou virão a ser médicos: o olhar. Um olhar treinado, que classifica e que, principalmente, é capaz de diferenciar o "normal" do "patológico", é uma das ferramentas mais valorizadas para um bom diagnóstico.

Nesse contexto, o próprio sexo, como apontei em outro artigo $^{34}$, emerge como uma categoria médico-diagnóstica. Olhar o sexo e descobrir a verdade sobre ele, ou seja, diagnosticá-lo, é um processo complexo, que envolve disputas e negociações entre os profissionais médicos e no que se refere a seus campos de conhecimento. Há uma busca incessante em saber onde, afinal, inscreve-se a diferença entre os sexos. É nesse sentido que, nas classificações médicas, o sexo é percebido como impresso em diferentes níveis - molecular, cromossômico, gonadal, hormonal e psicológico ${ }^{35}$ - sendo que a construção anatômica aparece como a última etapa de um processo onde se procura realinhar o corpo com a natureza de um sexo que já o habita. Fui assistir a uma palestra sobre diferenciação sexual em outro hospital, juntamente com meus informantes, na qual o palestrante, um geneticista, parece ter resumido essa idéia:

Uma coisa é sexo, outra coisa é gônada, outra coisa é cariótipo, etc., outra coisa é gênero, mas nem sempre uma coisa combina com a outra. $\mathrm{O}$ que a gente queria é que tudo combinasse, né?

\footnotetext{
${ }^{34}$ MACHADO, Paula Sandrine. "Quimeras" da ciência: estudo antropológico sobre as representações de profissionais da saúde acionadas em casos de genitália ambígua. Artigo apresentado como produção final exigido aos ganhadores do Concurso Anpocs-Clam-Ford Sexualidade e Ciências Sociais - Edital 2003 (no prelo).

${ }^{35}$ ID., IB.
} 
O sexo dos anjos

A aparência e, mais especificamente, o parecer com (um pênis ou uma vagina natural), assume uma importância fundamental no período pós-cirúrgico e o resultado estético ou cosmético dos genitais construídos emerge como uma das preocupações peculiares à cirurgia. As técnicas cirúrgicas são empregadas no sentido de tornar a genitália da criança $o$ mais próximo possível do normal, de acordo com determinados padrões de tamanho, forma, terminação do trajeto urinário (mais na ponta do pênis para os meninos; mais abaixo nas meninas) $e$ uso (construir vaginas "penetráveis" e pênis "que penetrem").

O sexo deixa, assim, de ser natural na medida em que é a técnica cirúrgica, associada a intervenções medicamentosas, e o olhar da ciência que o constrói. A fala de um dos cirurgiões sobre o aprendizado da técnica em casos de "correção" genital é, nesse sentido, bastante ilustrativa:

É uma coisa nova, diferente [o procedimento cirúrgico], e às vezes eles [os médicos residentes] não conseguem imaginar antes como é que ficaria a cirurgia. Então, pra eles, é uma surpresa. Eles vão vendo os detalhes, a transformação. Então, às vezes não conseguem enxergar aquela genitália como ou masculina ou feminina. Com o tempo, termina a cirurgia, eles geralmente verbalizam isso.

Da mesma forma que os profissionais médicos, as famílias das crianças que foram submetidas a algum tipo de cirurgia de "correção" da genitália, devido ao diagnóstico médico de genitália ambígua, possuem seus próprios critérios para examinar $e$ classificar o sexo dos bebês. Esses critérios, apesar de também adotarem como elemento central a aparência, podem, no entanto, não levar a conclusões idênticas às dos profissionais de saúde. Mesmo quando há um acordo sobre o sexo que se olha, os critérios de diagnóstico e intervenção biomédicos, voltados para a normatização corporal, nem sempre estão relacionados às representações de sexo e de gênero das famílias envolvidas. 
Antes mesmo que a equipe de saúde tivesse se reunido para decidir que procedimento cirúrgico seria tomado no caso de Hariel, havia um boato de que sua mãe, Carolina, já estava chamando a criança de meu filho. O consenso quase geral da equipe sobre a mãe era de que ela estaria ainda sob o impacto da notícia, negando a má formação do bebê. Entrei em contato com Carolina e sua mãe (avó de Hariel) em uma de suas primeiras consultas de retorno ao ambulatório de cirurgia pediátrica, quando Hariel já havia sido "diagnosticado" como um menino, o qual necessitaria de cirurgias para correção de hipospádia e para colocar seus testículos na bolsa escrotal. Evidentemente que algum tempo já havia se passado $e$ as duas não estavam mais no contexto de uma internação hospitalar, o que não deve ser desconsiderado, mas quando perguntada sobre o que havia sentido no momento em que recebeu a notícia, Carolina me respondeu que, desde sempre, a família achava que a criança era um menino. Perguntei o que os fazia pensar assim e ela me respondeu, rindo, que era por causa do jeitão de Hariel e de sua aparência. Carolina nunca teve dúvidas de que ele tinha um pênis.

O caso de Hariel foi muito curioso, pois, do ponto de vista médico, apresentava uma intensa complexidade. $\mathrm{O}$ resultado do cariótipo realizado na criança indicava a presença de um cromossoma $\mathrm{X}$ e um outro que tudo indicava ser um Y com uma deleção cromossômica. O que a equipe procurava na genética da criança, Carolina percebia com clareza no jeitão de Hariel. Onde a equipe ainda via um falus - termo utilizado para não definir a estrutura vista como um clitóris ou um pênis, como explorarei mais adiante - Carolina já via um pênis.

Percebe-se que a aparência é algo em negociação social desde o momento do nascimento e que assume um forte papel na vida das crianças operadas. A negociação específica que estou analisando aqui é aquela que ocorre entre os olhares de diferentes atores sociais: o dos profissionais médicos, que estão imbuídos, na nossa cultura, do poder de "diagnosticar o verdadeiro sexo"; e o 
O sexo dos anjos

das crianças/jovens intersex e seus familiares, aqueles a quem embora não seja dado o poder de diagnosticar o sexo elaboram hipóteses sobre o mesmo.

A nomeação daquilo que se vê possui uma importância fundamental nessa discussão e parece ser a instância onde as representações sobre a ambigüidade são freqüentemente acionadas. De acordo com a lógica biomédica, o que é considerado confuso, nos corpos das crianças intersex, são os genitais incompletos, mal-formados, que devem ser, portanto, corrigidos. Nesse sentido, emerge a idéia de que o sexo, em si, não é ambíguo, na medida em que se pressupõe que ele está localizado em alguma instância, em sua natureza feminina ou masculina. Assim, como aponta Kessler ${ }^{36}$, a ênfase é dada no fato de que os médicos estão completando genitais e não que estão criando gênero.

Essa concepção de que o sexo só pode ser de homem ou de mulher e de que não se trata, nunca, de uma variação do padrão masculino/feminino, mas sim de uma natureza a ser completada, é aparentemente contraditória àquela dos diferentes níveis em que se situa o sexo. É aceito que o mesmo está impresso em variados locais no corpo humano e que é justamente isso que faz com que diferentes critérios sejam considerados no processo de tomada de decisão quando se está frente a um caso de intersexo. No entanto, pode-se dizer que um dos níveis, o anatômico, é eleito como fundamental exatamente porque é aquele considerado capaz de remeter ao "sexo verdadeiro" através da genitália construída.

Há uma ênfase enorme, por parte dos profissionais de saúde, dada aos termos que devem ser utilizados para definir os genitais de forma a não confundir as famílias. Existe todo um cuidado em não associar estruturas que não possam ser classificadas nem como femininas nem como masculinas a termos que se refiram a um ou outro sexo. Utilizando o argumento de

${ }^{36}$ KESSLER, S. Lessons from the... Op. cit. 
Bourdieu ${ }^{37}$ de que nomear é criar algo, essa seria uma forma de não sugerir um sexo sem ter "certeza" da sua existência. Estabelecem-se, assim, denominações passageiras, como falus (que não é nem um clitóris nem um pênis), e fendas labioescrotais (que não são nem os grandes lábios, nem o escroto). Um dos informantes explica:

(...) uma das coisas importantes, na primeira notícia, é nunca utilizar gênero, assim, "a menina", "o menino", "a bebê", "o bebê". É sempre "o recém nascido", ou "o bebê". Usa um termo geral, assim, neutro, né, que não sirva pra nenhum dos lados. Mesmo ao se referir sobre as estruturas vistas; "... parece um pênis, parece um clitóris", não. Aquela estrutura é um falus, né, que se chama. É o termo que se usa, médico, latim, de pênis. Porque a gente não sabe em que aquilo pode se transformar, ou qual a origem daquela estrutura. (Grifos meus)

É como se, ao nomear e ao pressupor a existência de uma estrutura como masculina ou feminina, ela automaticamente se transformasse em uma espécie de elemento anatômico generificado. Isso se torna particularmente explícito nas crianças com cariótipo 46XX que nascem com Hiperplasia Adrenal Congênita. No momento em que é feito esse diagnóstico, é assumido que o sexo verdadeiro é feminino e a estrutura que se vê passa imediatamente de falus a clitóris aumentado, independente, nesse momento, da medida do órgão, seja ele um pouco acima do tamanho considerado normal pela bibliografia médica (acima de 0,9 $\mathrm{cm}$ ) ou mesmo maior que o tamanho mínimo esperado para um pênis considerado normal $(2,5 \mathrm{~cm}) .^{38}$

É interessante perceber que se utiliza uma palavra latina, falus, para tentar amenizar a questão da (in)definição, a qual, paradoxalmente, é bastante generificada na linguagem corrente.

${ }^{37}$ Bourdieu, P. Ce que parler... Op. cit.

${ }^{38}$ KESSLER, S. Lessons from the... Op. cit. 
O sexo dos anjos

Como reconhece o próprio informante em sua fala, o termo é o equivalente, em latim, de pênis. Esse fato apenas reforça a análise que realizei anteriormente de que é realmente difícil encontrar, em nossa cultura, categorias classificatórias que escapem do sistema dicotômico. Na linguagem, a conseqüência mais imediata traduzse na dificuldade de utilizar - e mesmo de imaginar - termos neutros no que se refere à diferenciação sexual.

Houve uma situação que aconteceu no contexto do hospital enquanto eu acompanhava uma parte da consulta de Caliel, recém operado para "correção" de hipospádia peniana. O pai, um tanto reticente, perguntou ao cirurgião pediátrico sobre uma pele que ele estava percebendo ao redor do pênis do menino. Segundo ele, essa pele era parecida com uma... Antes que completasse a frase, já prevendo que o pai estava se referindo à semelhança daquela estrutura com uma vagina, o médico se antecipou: Não, isso é gordura. Essa situação remete ao fato de que o olhar e a posterior nomeação apresentam-se como importantes elementos também para os familiares da criança. No extremo, às vezes é preferível não olhar muito, como ocorreu com a mãe de uma recém-nascida que preferiu ficar conversando comigo enquanto a filha estava sendo examinada, próxima à porta e distante da equipe, porque não queria ver.

É também conversando com os pais de Caliel que tenho acesso a outro tipo de divergência que pode existir entre as classificações médicas e as ditas "leigas". O casal apresentava-se bastante inseguro quanto à necessidade de submeter o filho a um procedimento cirúrgico tão precocemente e pediram um tempo para pensar melhor antes de tomarem uma decisão. Conversei com eles na sala de espera em seu retorno ao ambulatório. Eles me referiram saber que o menino tinha hipogonadismo e micropênis. Perguntei o que sabiam sobre esse termo, micropênis, e me responderam que era um pênis menor que o dos outros. Continuamos a conversa $e$, de repente, entre risos, o pai de Caliel me contou que ele próprio possuía um pênis pequeno, assim como o seu pai, mas que, nem por isso, deixou de ter uma esposa 
e um filho. Isso justificava, indiscutivelmente, a sua dúvida e a de sua esposa quanto à necessidade de operar a genitália de seu filho.

É interessante notar que se admite, entre os médicos, que o olhar esteja sujeito a enganos, o que, no entanto, é atribuído a profissionais com menor experiência, como os estudantes, residentes e médicos menos treinados ou com menor competência. Mas mesmo médicos experientes podem se enganar, como no caso relatado pela esposa de um dos cirurgiões sobre como ele confundiu a filha, através da ecografia, com um menino, pois identificou algo que considerou um pênis. O obstetra também já estava concordando com a observação e os dois só se convenceram do contrário após a amniocentese, exame que fornece o cariótipo do bebê na gestação.

Os corpos vão sendo, assim, classificados e percebidos como masculinos ou femininos e há toda uma engenharia tecnológica, no caso da medicina, dedicada a encontrar o "sexo verdadeiro", apesar de todas as variações que a anatomia possa apresentar e de todas as incertezas da própria medicina. Através de outros recursos, as famílias também estabelecem critérios para pensar os corpos das crianças como femininos ou masculinos, com a diferença que nem sempre é necessária uma modificação anatômica, por meio de procedimentos cirúrgicos, para que esse corpo seja percebido como "dentro da norma".

Os corpos intersex são, portanto, emblemáticos, justamente porque desafiam o sistema binário de sexo e de gênero, bem como escrutinam, em diferentes esferas sociais, os critérios utilizados para que alguém possa ser considerado homem ou mulher. Esses critérios variam de acordo com a lógica cultural utilizada pelos atores sociais, tanto que um mesmo corpo de bebê, conforme tomei conhecimento em campo, pode ser classificado como do sexo feminino e do sexo masculino por pessoas diferentes. Logo, a certeza anatômica corresponde ao imperativo social de classificação binária dos corpos, onde um terceiro, que não pode ser encaixado em nenhuma das categorias ou que 
O sexo dos anjos

poderia ser incluído nas duas, será percebido como impuro, perigoso e fora do lugar. ${ }^{39}$ No limite, a variação, entendida pelos médicos como ambigüidade, é vista como não natural, ainda que engendrada pela própria biologia.

Suzanne Kessler $^{40}$ aponta como, para os profissionais médicos, o que está em jogo é uma outra idéia de natureza que não corresponde, necessariamente, àquela compartilhada pelas crianças/jovens intersex e seus familiares. De acordo com a autora, o corpo submetido às intervenções cirúrgicas e medicamentosas é considerado natural na medida em que ele é inserido na norma $e$ que esta, por sua vez, também é percebida como natural. Nessa mesma linha de raciocínio, Kessler, apontando alguns elementos sobre as cirurgias plásticas, mostra como, em muitas situações, a noção de "natural" e de "ideal" acabam se sobrepondo e a produção do "ideal" acaba sendo, em última análise, pensada como a produção do "natural".

Como conseqüência lógica desse argumento, o corpo não "corrigido" será considerado não natural. É interessante pensar que, nessa perspectiva, o natural se torna cultural na mesma medida em que o cultural se naturaliza ${ }^{41}$. Nesse deslizamento entre natureza e cultura, a análise de algumas situações específicas relacionadas ao intersexo e da forma como profissionais médicos, intersexuados e suas famílias lidam com elas aponta para ainda mais dois níveis através dos quais o sexo é considerado: um que remete à sua visibilidade $e$ outro à sua invisibilidade. Esses dois níveis também pesam no momento da tomada de decisões em torno da "cirurgia reparadora" dos genitais e servem como chave de análise para a categoria ambigüidade.

${ }^{39}$ Douglas, Mary. Pureza e Perigo. Lisboa, Edições 70, 1991.

${ }^{40}$ KESSLER, S. Lessons from the... Op. cit.

${ }^{41}$ RABINOW, Paul. Artificialidade e iluminismo... Op. cit. 
Paula Sandrine Machado

Retalhos, fissuras e outras coisas do gênero: apontamentos sobre a visibilidade $e$ a invisibilidade do sexo.

Reyel tinha 13 anos quando a conheci no ambulatório de cirurgia pediátrica. Diagnóstico médico: hiperplasia adrenal congênita, genitália ambígua. Bastante tímida e em companhia da mãe, não falou muito comigo, embora sorrisse quando me dirigia a ela. Encontro com Reyel outro dia, também no ambulatório, ocasião em que iria marcar sua segunda cirurgia, uma vaginoplastia. $\mathrm{Na}$ sala de espera, enquanto estávamos conversando, pergunto sobre a cirurgia e ela, com um riso tímido, diz: "Vão acabar de me tirar o couro".

Seheiah tinha 14 anos. Em 2001, com 11 anos, abandonou o tratamento hormonal que vinha realizando para hiperplasia adrenal congênita. Havia sido, quando bebê, submetida a uma clitoroplastia. Quando encontrei Seheiah pela segunda vez, também estava no ambulatório de cirurgia pediátrica, no mesmo dia que Reyel, para marcar, igualmente, uma vaginoplastia. Seheiah usava boné, vestia uma bermuda bem larga e uma camiseta preta. Por ter interrompido o tratamento com hormônios, seu crescimento foi um pouco prejudicado e, além disso, teria o que é socialmente (e biologicamente) considerado como "traços masculinos": voz mais grossa, ombros largos, pêlos pelo corpo.

Seheiah, assim como várias outras crianças definidas como meninas ao nascer, provoca na equipe médica uma reação muito característica. "Mas é um gurizinho!" é uma das expressões que podem ser escutadas para descrever o espanto causado pela sua fisionomia. Nesse dia, foi inevitável a comparação com Reyel, considerada um "sucesso" do ponto de vista da equipe. "Ela é bem menininha, feminina". Um dos informantes, expressando o desconforto gerado pela figura de Seheiah, considerou: "É bom já alertar os pais. Às vezes, a gente fala alguma coisa e a família cuida, e aí melhora".

Todas as crianças $e$ jovens com Hiperplasia Adrenal Congênita com as quais tive contato até agora foram submetidas a 
O sexo dos anjos

cirurgias de "correção" da genitália para o sexo feminino. Do ponto de vista médico, são os casos de mais fácil resolução, na medida em que não se têm dúvidas de que se trata de uma mulher biológica. No entanto, surgem desconfianças de outra ordem, especialmente no que se refere à masculinização fenotípica que muitas dessas crianças acabam desenvolvendo. Levanta-se, por exemplo, a questão de se a exposição do feto a um grande estímulo de andrógenos durante a gestação não poderia afetar o comportamento futuro dessas meninas, direcionando-as para opções "mais masculinas", o que inclui, evidentemente, a orientação sexual para pessoas do mesmo sexo, o gosto pelo futebol e por brincadeiras mais "ativas", bem como a personalidade marcada por traços indicativos de "molecagem". Nas descrições dos atendimentos psicológicos em prontuários e nas discussões de caso em equipe, outros elementos que parecem freqüentemente ligados a essas meninas são a agressividade $e$ uma possível confusão entre comportamentos e/ou gostos masculinos e femininos.

As representações corporais $e$ as práticas sociais acionadas no manejo de crianças com Hiperplasia Adrenal Congênita, bem como com Hipospádia e Criptorquidia, guiam o segundo eixo de análise desse estudo, que se propõe a trabalhar com o que categorizei como as visibilidades $e$ as invisibilidades do sexo. Conforme já apontado, articulo dois níveis distintos, o social e o anatômico, onde essas categorias se apresentam.

Retomando esses dois diagnósticos médicos, na Hiperplasia em crianças com cariótipo 46XX ocorre, entre outras características corporais, o desenvolvimento do que é denominado clitoromegalia (aumento do clitóris). No caso das hipospádias penianas combinadas com criptorquidia, são crianças com cariótipo 46XY que, entre outras conseqüências, dependendo da severidade da hipospádia, podem vir a ser "corrigidas" como meninas ou, também, desenvolverem um micropênis.

A tomada de decisões médicas no que se refere às cirurgias "reparadoras" da genitália em crianças intersex está baseada em 
uma série de critérios que variam de acordo com o sexo que se pensa em construir. Para o sexo feminino, os fatores mais levados em consideração, em ordem de importância, são: a capacidade reprodutiva e a possibilidade de reconstrução anatômica de uma vagina que possibilite mais tarde, para a mulher, relações sexuais prazerosas (o que é associado à preservação das enervações do clitóris) e que possa ser penetrada por um pênis. Para o sexo masculino, aparecem os seguintes fatores, também em ordem de importância: o tamanho e a capacidade erétil do pênis; a possibilidade de sentir prazer (o que é associado à ejaculação) $e$ de penetrar adequadamente uma vagina; a capacidade reprodutiva; $e$ a capacidade de urinar de pé. ${ }^{42}$

Esses critérios apontam para elementos estéticos a serem observados, conforme já assinalado, e também à avaliação do que é considerado mais funcional como, por exemplo, a preservação da capacidade reprodutiva e sexual. A questão da funcionalidade do corpo está bastante imbricada com aquilo que se espera socialmente de homens e mulheres. Assim, se a capacidade reprodutiva desponta como elemento preponderante nas decisões de definição para o sexo feminino, o desempenho sexual (penetrativo, com pênis de tamanho e capacidade erétil considerados adequados) ocupa o mesmo papel para o sexo masculino. ${ }^{43}$

O elemento estético combinado à funcionalidade engendra mais dois outros níveis onde o "sexo verdadeiro" é procurado: o da visibilidade e o da invisibilidade, pensados, basicamente, em termos sociais e anatômicos. É nesse cenário que será avaliado se há uma coerência entre o sexo construído e os estereótipos masculinos ou femininos esperados para aquele sexo. Conforme aponta Corrêa ${ }^{44}$, essa "coerência entre a aparência e a essência", fundamentada no dimorfismo sexual, já era um fator considerado central para avaliar o sucesso da intervenção desde a época de

${ }^{42}$ MACHADO, P. S. "Quimeras" da ciência... Op. cit.

${ }^{43}$ ID., IB. 
O sexo dos anjos

Money. Salienta-se ainda a expectativa de que se cumpra uma norma heterossexual que pressuponha a capacidade para o sexo penetrativo.

Segundo Sumi Colligan ${ }^{45}$, em um artigo onde analisa os paralelos entre as representações $e$ as lutas cotidianas de grupos de pessoas intersex àquelas de pessoas com deficiência, em ambos os casos elas são submetidas a diagnósticos médicos de anomalias, bem como são silenciadas e impelidas à "correção". Ao abordar especificamente o tratamento dispensado às pessoas intersex, a autora aponta que os profissionais médicos supõem uma linearidade entre os genitais e o gênero a ser desempenhado e que a "reparação" dos genitais pode ser entendida como uma forma de reabilitar esse corpo "desviante" à inserção social dentro dos parâmetros da heterossexualidade.

$\mathrm{O}$ reverso disso acontece quando se considera que alguém está, de antemão, impossibilitado para a prática sexual, o que provoca readequações na perspectiva médica de que a operação é uma conduta inevitável. Jelial tem pouco menos de dois anos e possui uma síndrome orgânica que ocasiona uma série de "malformações" corporais. No entendimento da equipe, ela não teria, ao crescer (caso sobreviva), possibilidade de relação sexual. A decisão foi a de que não seria preciso construir-lhe uma vagina, mas apenas um orifício, para que ela não sinta dores em função do impedimento da saída da menstruação. Fica claro, também aqui, que a reconstrução de uma vagina ou de um pênis é uma reivindicação social.

$\mathrm{Na}$ hiperplasia adrenal congênita, o que estou considerando como elementos socialmente invisíveis do sexo diz respeito a aspectos genéticos e gonadais/hormonais. Já a visibilidade social do sexo é dada pelos traços físicos e pela anatomia, mas não

${ }^{44}$ CORRÊA, M. Não se nasce... Op. cit.

${ }^{45}$ Colligan, Sumi. Why the Intersexed Shouldn't be Fixed: Insights from Queer Theory and Disability Studies. In: SMITH, Bonnie G.; HuTCHISON, Beth. (eds.) Gendering Disablility. London, Rutgers University Press, 2004, pp.145-165. 
Paula Sandrine Machado

apenas aquela que se refere aos genitais. Esses últimos, tanto no caso de meninos como no de meninas, adquirem visibilidade através do olhar dos médicos e da família, conforme apontei anteriormente. Além do papel que desempenha para os pais (e suas relações com vizinhos, parentes e outros amigos), a anatomia dos genitais é pensada enquanto um futuro elemento a ser tornado visível nas relações sexuais e que deve ser funcional na relação com o sexo oposto.

Qualquer discordância entre a genitália construída e o gênero que se espera que aquela criança venha a desempenhar gera um grande incômodo para os profissionais médicos, o que nem sempre acontece com as famílias. Há um caso muito elucidativo disso que é o de Lecabel. Ela nasceu em uma cidade do interior do estado do Rio Grande do Sul, com HAC e, desde pequena, foi criada como menina, apesar do aumento de seu clitóris. Fiquei sabendo que a mãe de Lecabel teria escondido a situação do seu círculo de relações, inclusive de seu marido. A menina chega ao ambulatório aos 15 anos, com um clitóris medindo 15 centímetros. A sua queixa girava em torno da ausência de menstruação e da falta de crescimento das mamas. De acordo com um dos estagiários de Psicologia que a atendia, Lecabel nunca teve dúvidas quanto ao fato de ser mulher. No entanto, a visibilidade de seu clitóris a tornava, dentro dos parâmetros de normalidade adotados pelos profissionais de saúde, "anômala". Daí, a avaliação da necessidade da cirurgia para "corrigir seus genitais". Como aponta um dos informantes:

Porque imagina pra uma menina que... que vai ter um namorado, como a Lecabel. Vai ter um namorado, o namorado tá lá, quer uma coisa mais aprofundada, uma intimidade mais aprofundada, e, colocando a mão, sente um pênis. Entendeu? Então é arriscado ela até apanhar. [Paula: Mas nem todos os clitóris ficam tão aumentados quanto o dela, né?] É. Nem todos os clitóris ficam tão aumentados quanto o dela, mas eles ficam avantajados. No mínimo, um clitóris de uma mulher normal tem o quê? Um 
O sexo dos anjos

centímetro, dois centímetros? E uma menina dessas vai ter o quê? No mínimo cinco centímetros. Então é uma coisa bem avantajada, entendeu?

Outro cirurgião também relatava, um dia, sobre uma menina com HAC, que sentia vergonha quando seu clitóris ficava ereto. Ao andar pela praia de biquíni, não apenas o clitóris, mas a ereção tornavam-se visíveis, tal como no caso de Lecabel. Nessas duas situações, há pelo menos três elementos que merecem ser destacados. O primeiro deles diz respeito ao perigo que representa a visibilidade do sexo e da excitação feminina. A referência aos problemas que pode gerar um clitóris avantajado é bem elucidativa desse fato. $\mathrm{O}$ segundo elemento remete à preocupação com um corpo desarmônico. Por último, destacam-se as diferentes estratégias que são tomadas no sentido de lidar com a homossexualidade feminina e com a masculina. É sobre esse último ponto que dedicarei maior atenção.

Segundo o relato dos profissionais de saúde, a homossexualidade feminina não parece ser uma grande preocupação tanto para eles como para as famílias com as quais têm contato. Já a homossexualidade masculina, de acordo com eles, é temida pelas famílias, que pedem garantias quanto a futura masculinidade heterossexual das crianças que serão submetidas a cirurgias de reconstrução peniana. Se por um lado, no que se refere às meninas, a maior preocupação parece ser com a desarmonia entre as características visíveis do corpo e o genital construído, por outro, em relação ao menino, há um medo maior de que um pênis não funcionante não seja capaz de constituir um homem completo. Pode-se, mesmo, aventar a hipótese de que há um cuidado despendido pelos profissionais no sentido de preservar a masculinidade.

Acredito que isso explique em parte por que se observa uma quase impossibilidade de optar a se transformar uma criança com cariótipo 46XX em um menino, enquanto que o inverso não é verdadeiro. No primeiro caso, parece que o risco da feminilização 
e da construção de um pênis não funcionalé pensado como muito grave e definitivo para a masculinidade. Conforme aponta Kessler $^{46}$, quando se está pensando em homens, avalia-se o papel do pênis para a sua sexualidade, mas qual o papel da retirada do clitóris para a sexualidade feminina? A fala do profissional de saúde é reveladora dessas diferentes avaliações:

Às vezes tanto no menino como... Mais no menino do que na menina [acontece a preocupação com a homossexualidade], né? A homossexualidade feminina, nesses casos, me parece uma coisa ainda muito... parece lá... Se tu tens genitais normais não vai acontecer nada contigo, né? [Paula: Com a menina tu achas que isso é mais...] É. É mais velado. Ainda é um tabu mais assim, né? [Paula: Aham. E com menino é mais explícito?] Claro. Porque se tu não tem um pênis adequado... Porque a sexualidade está associada a um genital normal.

Talvez o médico esteja justamente apontando para o fato de que a homossexualidade feminina é muito mais invisível que a masculina. ${ }^{47}$ Obviamente que a possibilidade de uma transgressão no que se refere às parcerias sexuais não é desejada nos dois casos, mas a homossexualidade masculina parece ser muito mais evitada. Existem, assim, alguns sinais que se mostram mais desafiadores em relação à desejada harmonia sexo definidogênero: cabelos compridos em meninos e cabelos curtos em meninas; não colocar brinco em meninas; passividade nos meninos; gosto por jogos ou brincadeiras consideradas mais masculinas, como o futebol, para as meninas; entre outros.

Nesse sentido, a validação do trabalho médico ocorre quando se produz um corpo que seja adequado à definição que

${ }^{46}$ KESSLER, S. Lessons from the... Op. cit.

${ }^{47}$ MEINERZ, Nádia Elisa. Entre mulheres. Estudo etnográfico sobre a constituição da parceria homoerótica feminina em segmentos médios na cidade de Porto Alegre. Dissertação de Mestrado, Instituto de Filosofia e Ciências Humanas, UFRGS, 2005. 
O sexo dos anjos

lhe foi atribuída, ou seja, onde o estereótipo masculino ou feminino se construa de forma mais harmônica. É preciso salientar, entretanto, que a leitura que se faz dos corpos depende de um contexto no qual eles estão inseridos, o qual dá significado a estes corpos. Seria necessário um maior investimento etnográfico nesse aspecto, mas parece que existem situações em que os sinais corporais, ainda que indicando, por exemplo, a "masculinização de um corpo feminino", não soam tão desarmônicos. Isso me chamou a atenção no caso de Lauviah, estudante de fisioterapia e que pertence a um segmento social financeiramente um pouco diferenciado. Apesar dos traços físicos (ombros largos e baixa estatura, por exemplo), não ouvi comentários por parte da equipe em relação a isso quando consultou. A forma como apresentava seu corpo, deslocava-o de um corpo masculino para um corpo esportivo (ela vestia calça jeans e blusa regata cavada, deixando à mostra seus ombros largos, que poderiam ser facilmente associados aos de alguém que pratica atividades físicas).

De qualquer modo, a cirurgia e o tratamento hormonal se propõem a minimizar a visibilidade de um "sexo" que não corresponda ao designado. No entanto, percebe-se que a cirurgia, em particular, não soluciona o problema da ambigüidade, especialmente no caso das meninas com HAC. Como sugere Elizabeth Zambrano ${ }^{48}$, acerca dos sentimentos dos transexuais no momento pós-cirúrgico, a cirurgia de troca de sexo não muda nada do ponto de vista social. A ambigüidade segue sendo uma marca desses corpos. No que se refere ao intersexo, esse fato ganha ainda outras tonalidades, na medida em que a construção do sexo se dá sobre um corpo que se considera indeterminado ou incompleto, para utilizar o termo êmico. Essa "indeterminação", em última análise, constitui uma marca extremamente importante

${ }^{48}$ ZAMBRANO, Elizabeth, Trocando os documentos: um estudo antropológico sobre a cirurgia de troca de sexo. Dissertação de Mestrado, Instituto de Filosofia e Ciências Humanas, UFRGS, 2003. 
Paula Sandrine Machado

na vida das pessoas intersex e de suas famílias. Há, nesse sentido, a marca do órgão "reconstruído", que não é natural, e, além disso, existe o desconhecimento sobre um corpo que "talvez pudesse" ter sido diferente.

\section{O que (re)faz o sexo? Algumas considerações finais}

Durante algum tempo - e ainda atualmente, em alguns contextos - a frase "It is easier to dig a hole than to erect a pole" ("É mais fácil cavar um buraco que erigir um poste") era amplamente utilizada pelos médicos para se referirem à facilidade técnica de construir genitais femininos e a correspondente dificuldade em se produzir genitais masculinos funcionais. A história das intervenções realizadas em corpos de crianças intersex mostra que, com os progressos biotecnológicos, muitas mudanças ocorreram nesse campo. As técnicas de diagnóstico e de intervenção cirúrgica e medicamentosa se tornaram mais sofisticadas, a ponto de tornar a famosa frase obsoleta para aqueles profissionais considerados melhor treinados $e$ mais atualizados. A facilidade técnica, pelo menos no hospital onde tenho realizado o trabalho de campo, não aparece como um critério relevante no processo de tomada de decisões quando se trata da "definição" do sexo de uma criança.

As representações de sexo e gênero acionadas pelos profissionais médicos quando são chamados a tomar uma decisão desse tipo são elementos fundamentais a serem considerados. Assim como os familiares das crianças intersex possuem hipóteses sobre o sexo do bebê baseados em determinados elementos que ganham sentido quando analisados a partir de seus valores sociais, os profissionais de saúde também aprendem a ver a anatomia $e$ esse aprendizado não está menos perpassado por condicionantes culturais. Apesar das diferenças que possam existir entre os dois posicionamentos sobre o corpo, eles convergem em um ponto: ambos partem do pressuposto hegemônico do dimorfismo sexual. Ao mesmo tempo, a própria existência de 
O sexo dos anjos

diferentes olhares sobre uma mesma anatomia $e$ a variabilidade apresentada pelos corpos intersex coloca em questão a suposta naturalidade da dicotomia.

$\mathrm{Na}$ interação entre médicos e familiares das crianças que nasceram com genitais considerados ambíguos, trava-se um debate entre diferentes concepções sobre a natureza, que resultam, inclusive, em diferentes opiniões sobre a anatomia. Assim, penso que a questão fundamental não está mais colocada no fato de que "se fazem mais mulheres que homens, porque tecnicamente é mais fácil". O que me parece particularmente mais desafiador, nas decisões que tenho acompanhado, são as formulações subjacentes aos discursos sobre a natureza do sexo.

Conforme discuti ao longo deste artigo, ainda que o sexo seja, às vezes literalmente, construído através de intervenções médicas e psicológicas, na perspectiva dos médicos trata-se de restaurar uma natureza incompleta. O sucesso terapêutico está em atingir uma harmonia minimamente satisfatória entre o sexo construído e o sexo verdadeiro localizado em algum lugar do corpo. Entre outros aspectos, essa harmonia será avaliada através de uma série de elementos, socialmente visíveis e significativos, como os traços físicos, os gestos e as condutas. Esse projeto, entretanto, nem sempre é bem sucedido, o que se observa muito freqüentemente nos casos de crianças 46XX, nascidas com HAC e definidas como meninas.

É importante ressaltar, em relação a isso, que, no que se refere às representações médicas, a idéia de natureza do sexo pode variar de acordo com o gênero que se imagina como o mais adequado para uma determinada criança. Assim, transformar um indivíduo XX em homem parece menos natural que transformar um indivíduo $\mathrm{XY}$ em mulher. Pode-se dizer que essa idéia está baseada em concepções mais amplas, que percebem a natureza feminina como passiva e a natureza masculina como ativa. Nesse sentido, não é que seja mais difícil construir um pênis e sim que é mais complexo construir um homem completo. Já no que se refere à mulher, a sua natureza passiva é denunciada desde as 
representações da biologia sobre o desenvolvimento embriológico do ser humano. Se é verdade que um corpo será feminino se não houver a ação da testosterona, marca hormonal da masculinidade, a mulher, em outras palavras, é o que não se tornou homem.

Entretanto, apesar das críticas que se possa fazer em relação a alguns elementos normatizadores constituintes do pensamento biomédico, não se pode desconsiderar que os médicos, no seu cotidiano, são chamados a tomar decisões muito difíceis e, no universo empírico que tenho acompanhado, fazem-no com muita seriedade. A equipe toma as decisões a partir de um corpo de conhecimentos bastante complexo, que inclui uma gama de elementos, fazendo com que cada conduta seja, também, um investimento pessoal. Longe de ser simples, o aprendizado da medicina onde se situa, entre outros conteúdos, o treinamento do olhar, é algo extremamente sofisticado. A grande lacuna, sobre a qual este artigo apontou alguns indícios, diz respeito ao fato de haver um reconhecimento apenas tímido de que esses saberes são provisórios, culturalmente construídos e que respondem a valores sociais mais amplos, como o do dimorfismo sexo-gênero no caso do manejo com a intersexualidade.

Desse modo, relativizar a naturalidade da dicotomia entre os sexos apresenta-se não apenas como uma questão teórica e conceitual, mas também como uma proposta ética e política. Evidentemente que essa discussão gera redirecionamentos nos estudos em sexualidade, mas é sobretudo na esfera cotidiana que as conseqüências desse argumento deveriam provocar deslocamentos, mesmo que, por hora, modestos. 